\title{
Re: Varicocelectomy to "Upgrade" Semen Quality to Allow Couples to Use Less Invasive Forms of Assisted Reproductive Technology
}

\author{
Samplaski MK1', Lo KC2, Grober ED2, Zini A3, Jarvi KA4 \\ 1 University of Southern California, Institute of Urology, Los Angeles, California, USA \\ 2 Mount Sinai Hospital, Department of Surgery, Division of Urology, Toronto, Ontario, Canada \\ ${ }^{3}$ McGill University, Department of Surgery, Division of Urology, Montreal, Quebec, Canada \\ ${ }^{4}$ University of Toronto, Institute of Medical Sciences, Toronto, Ontario, Canada
}

Fertil Steril 2017;108:609-612. doi: 10.1016/j.fertnstert.2017.07.017.

\section{EDITORIAL COMMENT}

Varicocele is the most common etiology of male-factor infertility. Varicocele repair is the simplest and the most cost-effective treatment way for infertile couples for natural conception. Recent data suggested that varicocele repair may reduce the need for invasive modalities of assisted reproductive technology (ART) for infertile couples. In this study, the authors tried to determine the degree of semen improvement after varicocelectomy and the effect of semen improvement on the need for ARTs. A total of 373 men who underwent varicocele repair were evaluated. Varicocelectomy was bilateral in $46.6 \%$ of patients and left in $53 \%$. Radiographic embolization was performed in $18 \%$ of patients and $82 \%$ was operated by microsurgical procedure. Overall total motile sperm count (TMSC) increased from $18.22 \pm 38.22$ to $46.72 \pm 210.92(p=0.007)$. The most significant increase was observed in men with baseline TMSC $<5$ million and almost 60\% of men were upgraded from in vitro fertilization (IVF) candidacy to intrauterine insemination or natural pregnancy. In conclusion, varicocelectomy has an important role in the treatment of male infertility and reduces the need for IVF treatment even in men with very low TMSCs.

\section{Emre Bakırcıoğlu, MD}

๑Copyright 2017 by the Association of Urological Surgery / Journal of Urological Surgery published by Galenos Publishing House. 